\title{
AC 2007-940: A PRIMER ON CAPACITY BUILDING
}

\section{Bethany Jones, United Arab Emirates University}

BETHANY S. JONES is James Madison Distinguished Professor at the James Madison University in Harrisonburg, Virginia. She recently completed an 18-month term as Dean of the College of Humanities and Social Sciences at the United Arab Emirates University in Al-Ain, UAE. Dr. Jones received her B.A. degree from Chestnut Hill College and her M.A. and Ph.D. degrees in French from Case Western Reserve University. Following her doctoral work, Dr. Jones held faculty appointments and administrative positions at Cleveland State University, the University of Delaware, Southwest Missouri State University, and then served as Vice President for Academic Affairs at James Madison University in Virginia 


\section{A Primer on Capacity Building}

Abstract: "Capacity building" is a phrase used frequently today in many contexts, but its definition and implications are too often unclear or misunderstood. Its rapid ascendancy into our vocabulary may leave the impression that it is an entirely new construct, although that is not the case. This paper will review some of the roots of the concept in the thinking of professionals, writers and activists from many fields. It will explore the multiple ways that "capacity building" is being defined today, with an emphasis on its use in connection with international development. And it will make the case for engineering educators to align themselves and their students with overseas projects which promise the best long range results for developing countries.

\section{Introduction}

The media have made aid to underdeveloped countries a staple item for the past few years. The Bill and Melinda Gates Foundation, with its vast resources, now makes headlines regularly. When Warren Buffett added his billions to it, interest grows. When those resources are turned to the eradication of malaria, HIV/Aids and TB, the public around the world pays even greater attention. Then add forays into Africa by stars such as Angelina Jolie, who returned to the US with an Ethiopian child in her arms, snatched from poverty into a life of predictable wealth. Then formerly large US foundations such as Ford, Carnegie and Rockefeller reveal that they are grappling with a changed landscape for donors of their size, their wealth transformed and downscaled in comparison with Gates-Buffett, and their goals, subsequently, brought under internal scrutiny, including their collaborative African initiatives. Recently, both Hurricane Katrina and the tsunami in Southeast Asia turned a spotlight onto emergency preparedness and humanitarian relief operations. As these events play out in public, development strategies aimed at the poorest countries have become a topic of considerable interest to the general public.

Engineering educators have special need to be familiar with the vocabulary of international development for several reasons. 1) The skills and competencies they possess, teach and practice are among the most valuable to countries trying to respond to critical events and improve their lot. 2) The emphasis on preparation of engineers for international practice has made overseas projects such as those associated with Engineers Without Borders attractive as a component of the undergraduate curriculum. 3) Making it possible for engineering students to indulge in both international travel and community service increases the attractiveness of engineering as a major.

But the world of development is increasingly specialized, complex, and politicized, making it difficult for many engineering educators to decide how to guide students who want to get involved in development initiatives. It is useful to look at development strategies involving engineers which already in place and weigh which might be the most best at providing students with academically solid experience as well as doing the maximum amount of good to the recipients. In particular, it is helpful to examine the notion of "capacity building," a popular concept that has passed into jargon, to see what characterizes it and how it differs from other, more familiar forms of development initiatives.

Capacity Building 
Capacity building as a development strategy attempts to solve some of the shortcomings of humanitarian relief and technical assistance as a type of foreign aid. The term "capacity building" in the development world first gained visibility as an outcome from a symposium "A Strategy for Water Sector Capacity Building" held in Delft in 1991 and organized by the United Nations Development Program (UNDP) and the International Institute for Hydraulic and Environmental Engineering. In the context of this symposium capacity building was defined as: The creation of an enabling environment with appropriate policy and legal frameworks; institutional development, including community participation (of women in particular); human resources development and strengthening of managerial systems.

UNDP recognizes that capacity building is a long-term, continuing process, in which all stakeholders participate (ministries, local authorities, non-governmental organizations and water user groups, professional associations, academics and others). [UNDP Briefing Paper, http://www.gdrc.org/uem/capacity-define.html, accessed on January 9, 2007]

In other documents, the UNDP states:

Capacity is the ability of individuals, organizations, and societies to perform functions, solve problems and set and achieve goals.

Capacity development entails the sustainable creation, utilization, and retention of that capacity in order to reduce poverty, enhance self-reliance, and improve people's lives. (NCAR site)

And from an UNDP sponsored meeting in Ghana in 2002, comes this advice: "Scan globally; reinvent locally."

The United Nations "Agenda 21" stated in 1992, "Specifically, capacity-building encompasses the country's human, scientific, technological, organizational, institutional and resource capabilities. A fundamental goal of capacity-building is to enhance the ability to evaluate and address the critical questions related to policy choices and modes of implementation among development options, based on an understanding of environmental potentials and limits and of needs as perceived by the people of the country concerned. As a result the need to strengthen national capacities is shared by all countries. . . . Skills, knowledge and technical know-how at the individual and institutional levels are necessary for institution-building, policy analysis and development management, including the assessment of alternative courses of action with a view to enhancing access to and transfer of technology and promoting economic development."

Among the objectives of Agenda 21 are "Shifting time horizons in programme planning and implementation addressing the developing and strengthening of institutional structures to enhance their ability to respond to new longer-term challenges rather than concentrate only on immediate problems."

As the phrase became better known, other organizations adopted it and added their own emphases. The Urban Capacity Building Network points out that "Local government, communities and NGOs are the main clients [of capacity building], but central government and 
the private commercial sector also need support." Counterpart International pointed out that "Another essential mechanism for capacity building is partnership development." A rapid scan of a variety of data bases comes up with the term associated with projects as far ranging as urban development, elementary education, information technology, toxic pollution, non-profit management, politics in Africa, service learning, justice systems, psychology, financing strategies, welfare reform, food security, indigenous populations, and bicycle parking schemes. The agencies involved in capacity building, the individuals, organizations of systems targeted by capacity building, the "clients" or intended beneficiaries of capacity building, the sources of funding and the definitions of successful capacity building and how it should be measured are all different. Non-specialists are to be forgiven for having a less than clear understanding of the meaning of capacity building, and for struggling to understand what makes it different from two other familiar development strategies, humanitarian relief/aid and technical assistance.

\section{Humanitarian relief}

Humanitarian relief - providing people with immediate basic needs for food, water, shelter, sanitation - is perhaps the most familiar form of aid since it features so strongly in media reports of natural and man-made disasters. The purpose of this aid is to sustain life and alleviate suffering, and emphasis is on rapid delivery of goods and services directly to affected people. Challenges may include setting up housing for 9000 people under adverse weather conditions, finding ways of feeding hundred or even thousands of people over sustained periods with no lead time, negotiating entry into disputed territories with warring parties in order to delivery medical supplies. Life, whether in a developed or developing country, is suddenly (think of Banda Ache and New Orleans) or chronically (think of Darfur) disrupted and help must be provided. While the generous nature of this work needs no explanation, in recent years a couple of issues have emerged to force a rethinking of how it might better be done. Unsettling stories came out about how many donors (countries, individuals and organizations) had to be pressured to make good on pledges for humanitarian relief. In addition, questions are being asked about the link between solving the immediate human crisis and improving the overall conditions of the people after the crisis is resolved is seldom articulated. Consider that if widespread vaccination programs are put into place in a development vacuum, that could result in the population of people living in poverty growing larger and living longer under persistent desperate conditions. Recently, leaders in relief agencies have begun to give thought how their work can fit within a more coherent development strategy, so that as a crisis is resolved, the work of improving the lives of the people can continue.

\section{Technical assistance}

Foreign aid, in the form of technical assistance, is urgently needed, but not necessarily deemed an emergency. In this it differs from much of humanitarian relief. Typically, experts in some field, often engineering, are called up (hired) to come to a region to perform a specific task. The advantage of this approach is that an outside expert can apply a proven solution to a problem efficiently and effectively. The disadvantage (which is becoming more and more apparent) is that the expertise leaves with the consultant, all too often with no ties to the permanent population. The missing link in foreign aid, especially in the use of imported technical assistance, has been tie-back with the indigenous people for sustainability. All too frequently the 
community in which the technical assistance is applied has no means of maintaining the organization or structure created for them. And the consultants have little or no leverage in seeing to it that their contribution will survive their departure. More damningly, leaders on the ground in Africa acknowledge: "Today, the goal of helping people in need is virtually becoming untenable, owning to bloody conflicts, corruption and excessive reliance of poor countries on handouts fro foreign donors who are reporting dwindling financial resources." (Africa News Service, April 8, 2004)

Another weakness in the technical assistance model is the very real through of burdensome and oppressive duplication of effort. A former diplomat from Fiji complained, for example, that his country has no ocean policy, pointing out that it is already pulled in all directions by ten different regional organizations with overlapping focus.

A perspective for engineering educators

The popularity of capacity building is directly attributable to growing dissatisfaction on the part of development specialists and the wider population with more traditional forms of assistance. Starting with William Easterly, but certainly not ending with him, questions have been raised about why massive infusions of foreign aid from developed countries into developing countries over the past several decades have brought about no discernable reduction in poverty or increase in living standards. And the strategy of importing specialist consultants for technical assistance has been brought into question by frequent reports of drop-in drop-out experts who leave behind equipment no one knows how to use, organizational models no one understands, and unfulfilled expectations. A capacity building approach, going back to its original defining documents, contains key elements which promise more results in the form of poverty alleviation. The key words are institution development; long-term; partnerships; sustainable; enhancement of selfreliance; technical know-how; transfer of technology and economic development, long-term challenges.

A report from Sierra Leone states: “. . . Capacity Building [is] a practical model that talks about the ability of poor communities to utilize the resources in their environment for human development with the help of government, NGOs and educational institutions, both internal and external. ... This concept ... is a process designed to achieve an end, meaning, empowering people in need with the requisite trainings and skills to arrive at self-sufficiency and selfreliance. The intent of capacity building is not only to transfer knowledge, but also to reduce or eliminate dependency and holistically address community needs."

So engineering educators would do well to examine possible international development initiatives in the light of what we are learning about the failings of past development strategies, and select for their students projects which bear the hallmarks of capacity building. One of the world's leading experts in development is Calestous Juma, Professor of the Practice of International Development at the Kennedy School of Government at Harvard University. In his address to the Royal Academy of Engineering in 2006, giving the Hinton Lecture, Professor Juma spoke on "Redesigning African Economies: The Role of Engineering in International Development." Juma's presentation outlined how reinventing engineering education was a key to Africa's future prosperity and self-sufficiency. He outlines changes that must be made in 
engineering education in Africa, including the reconnecting of instruction and research and training, and the aligning of research and academic degrees to societal needs. He calls for special emphasis to be placed on recruiting women into engineering, reforming the curriculum, redesigning the mission of individual colleges and universities, maximizing the collaboration between higher education and industry, and linking academic programs with local development needs for sanitation, agriculture, and entrepreneurship. In short, Juma is arguing for engineering education at the heart of capacity building in Africa. The time appears right for US engineering educators to take a clear-eyed look at development issues in poorer parts of the world, to assess where they and they students might make the best contribution in the long term, and then seek out the partners abroad who are poised to engage in capacity building with the help of partners from similar institutions.

Juma, Calestous. "Redesigning African Economies: The Role of Engineering in International Development." The Royal Academy of Engineering 2006 Hinton Lecture.

http://www.raeng.org.uk/news/publications/list/lectures/Hinton_Lecture_06.pdf (accessed on January 16, 2007)

"Defining Capacity Building," (n.d.) Retrieved January 9, 2007, from the Global Development Research Center Website: http://www.gdrc.org/uem/capacity-define.html

"Center for Capacity Building (CCB)," (n.d.) Retrieved on January 9, 2007, from the Center for Capacity Building Website: http://www.ccb.ucar.edu

Browne, Stephen, ed. Developing Capacity Through Technical Cooperation: Country Experiences. Earthscan Publications Ltd, London and Sterling, Virginia, 2002, p. x. On-line version, retrieved January 9, 2007.

“Agenda 21, Chapter 37," Retrieved January 15 from the Global Development Research Center Website: http://www.gdrc.org/uem/capacity-building.html

Massaquoi, Victor. "Capacity Building for Self-Reliance: A Holistic Approach. Standard Times, April 6, 2004. Retrieved July 12, 2004, from Africa News Service. 